\title{
Effect of Extracellular Matrix on Two Cell Lines Established from Mongolian Gerbil's (Meriones unguiculatus) Malignant Melanoma
}

\author{
Osamu HASHIMOTO, Kenji OGAWA, Masamichi KUROHMARU, and Yoshihiro HAYASHI \\ Department of Veterinary Anatomy, Faculty of Agriculture, The University of Tokyo, Bunkyo-ku, Tokyo 113, Japan
}

(Received 27 December 1994/Accepted 15 March 1995)

\begin{abstract}
We investigated the effect of extracellular matrix (ECM) on the adhesion, morphology and proliferation of two Mongolian gerbil's melanoma cell lines (MGM-S, MGM-A) which differed in malignancy. Fibronectin matrix was detected on the cell surface of MGM-S by immunofluorescence techniques. MGM-A cells, showing a multipolar shape, were widely spread over the dishes coated with fibronectin, laminin or type IV collagen. The adhesion rate of MGM-A cells to ECM components was higher compared to that in controls. Attachment to laminin was conspicuously promoted. The effect of laminin on MGM-A cell growth was also the highest among the substrates examined. On the other hand, these ECM components did not affect MGM-S cells. These results suggest that laminin and fibronectin may participate in the malignancy of MGM cell lines.-KEY wORDs: fibronectin, laminin, malignancy, melanoma cell line, Mongolian gerbil.
\end{abstract}

J. Vet. Med. Sci. 57(4): 635-640, 1995

A number of culture cell lines have been established from various tumor cells, which provide useful models for studying histogenesis and metastasis of tumors $[8,15,20$, $21,25,27]$. Recently, it was reported that the expression levels of adhesion molecules to the extracellular matrix (ECM) correlate with malignancy of tumor cells $[1,2,17]$. Laminin, a glycoprotein and a major component of basement membranes, facilitates the adhesion, proliferation and differentiation of tumor cells and promotes the malignant phenotype [3, 23 27]. Cells that adhere to laminin are more malignant than non-adherent cells [24, 26]. Furthermore, the number of laminin receptors correlates with the malignant potential of various tumor cell lines [16, 25]. Fibronectin, a glycoprotein, interacts with the cell surface as well as other ECM components. Transformation is often accompanied by degradation of fibronectin from the cell surface $[6,10]$. The reduction of fibronectin and its receptors is responsible for acquisition of tumorigenecity and anchorage independent growth [5, 7]. Therefore, characterization of malignant potential and affinity to the ECM in various tumor cell lines may provide information on progress of tumors.

Two cell lines from Mongolian gerbil's malignant melanoma have been described in previous reports $[9,18]$. The cell line derived from an intraperitoneally transplantable tumor, designated as MGM-A, has more malignant potential in same aspects than cells from a subcutaneously transplantable tumor (MGM-S). In this study, we investigated the effect of ECM on these cell lines.

MATERIALS AND METHODS

Cells and culture: MGM-A and MGM-S cells were cultured as reported previously $[9,18]$. These cell lines were grown in Eagle's minimum essential medium (MEM) supplemented with $10 \%$ fetal bovine serum (FBS: CSL Ltd., Australia) at $37^{\circ} \mathrm{C}$ in a humidified atmosphere of $5 \%$
$\mathrm{CO}_{2}$ in air.

Growth rate: MGM-A cells at the 153rd passage and MGM-S cells at the 143 rd passage were used. A total of $2 \times 10^{4}$ cells were seeded into culture dishes of $35 \mathrm{~mm}$ in diameter and incubated in MEM containing $10 \%$ FBS. Cell numbers in triplicate dishes were counted using a hemocytometer at $1,3,5,7,9,11$ and 14 days after seeding. The cell viability was assessed by trypan blue dye exclusion. The medium was renewed every 3 days.

Chromosome number: MGM-A at the 152nd passage and MGM-S at the 141st passage were used to determine chromosome numbers of these cell lines as previously described [9]. Chromosome numbers of 100 cells at metaphase were observed and counted microscopically.

Soft agar culture: To examine the anchorage dependent or independent growth of MGM cells, proliferation in semisolid medium was determined by seeding $10^{4}$ cells $/ 35$ mm-diameter dish in $0.85 \mathrm{ml}$ of medium containing $10 \%$ FBS and $0.3 \%$ bacto-agar (Difco, Detroit, MI, U.S.A.) on top of a solid layer of $2.5 \mathrm{ml}$ of $0.5 \%$ bacto-agar in the same medium. Plates were incubated for 2 weeks at $37^{\circ} \mathrm{C}$. The number of colonies containing more than 50 cells was determined microscopically.

Tumorigenecity: To clarify the in vivo relevance of the in vitro malignancy, MGM cells were homo-transplanted. Two male and two female gerbils of the TUM strain at 6 weeks of age were used for subcutaneous or intraperitoneal transplantation. Cells were harvested with trypsinization and suspended in phosphate buffered saline (PBS). A single suspension of $10^{7}$ cells in $0.5 \mathrm{~m} l$ of PBS were inoculated into each animal. The gerbils were necropsied at 10 days or 28 days after the injection. The size of produced tumors was calculated by measuring the dimension.

Immunofluorescence: It is generally accepted that fibronectin correlates with cell shape, anchorage dependent growth and tumorigenecity. We examined the 
localization of fibronectin on the cell surface by indirect immunofluorescent staining. For staining cellular fibronectin (cFN), cells grown on coverslips were fixed with acetone/methanol $(1: 1)$ for $5 \mathrm{~min}$ at $-20^{\circ} \mathrm{C}$. The specimens were treated with monoclonal antibody to $\mathrm{cFN}$ (Biohit, Finland) at 1:300 dilution and then with fluorescein isothiocyanate (FITC)-conjugated goat anti-mouse Ig G (Tago, Inc., Japan) at 1:100 dilution as a secondary antibody. They were mounted with $90 \%$ glycerol in PBS and observed with an Olympus BHK-RFK photomicroscope equipped with epiffuorescence optics.

Western blotting: Cells were grown in $60 \mathrm{~mm}$-diameter culture dishes until confluent. Dishes were rinsed 3 times with PBS, and cells were scraped and collected. Cell extracts were prepared in $20 \mathrm{mM}$ Tris- $\mathrm{HCl}$ (pH 7.4), 150 $\mathrm{mM} \mathrm{NaCl}, 1 \% \mathrm{CHAPS}, 2 \mathrm{mM}$ phenylmethylsulfonyl fluoride, $150 \mathrm{ku} / \mathrm{m} l$ Aprotinin. The resulting lysate was spun down and aliquots of supernatant were dissolved in Laemmli's [13] sample buffer and boiled for $5 \mathrm{~min}$. The samples were electrophoresed on SDS-polyacrylamide gels $(10 \%)$ under a reducing condition and transferred to Immobilon-P filters (Millipore Ltd., Japan). Filters were blocked with Block Ace (Dainihon-seiyaku Inc., Japan) and incubated overnight with anti-cFN $\mathrm{mAb}$ in $1: 1,000$ dilution, followed by incubation with horseradish peroxidase-conjugated goat anti-mouse IgG (1:1,000 dilution) for $1 \mathrm{hr}$ at room temperature. Filters were washed in $0.05 \%$ Tween-20 in PBS between each step and developed using the enhanced chemoluminescence detection system (Amersham, England).

Effect of ECM: To determine whether the affinity of the cell lines to ECM correlates with malignant potential, we examined the effect of ECM components on MGM cells.

For adhesion assay, culture dishes of $35 \mathrm{~mm}$-diameter were coated with various amounts of Matrigel, laminin, fibronectin or type IV collagen and incubated for a few hours at $37^{\circ} \mathrm{C}$. Prior to use, coated dishes were rinsed with serum-free MEM containing $0.05 \%$ bovine serum albumin (BSA). MGM-A or MGM-S cells were washed with MEM and detached with $0.05 \%$ trypsin and $0.02 \%$ EDTA in PBS. They were then suspended in serum-free MEM containing $0.05 \%$ BSA. Cells $\left(10^{5}\right)$ were added to each dish and incubated for $90 \mathrm{~min}$ at $37^{\circ} \mathrm{C}$. At the end of this period, dishes were gently washed 3 times with PBS to remove unattached cells. Attached cells were trypsinized and counted using a hemocytometer.

For growth study, wells of 24 well plates were coated with $5 \mu \mathrm{g}$ of laminin, fibronectin or type IV collagen. Cells $\left(5 \times 10^{4}\right)$, prepared as described above, were transferred to each well and incubated in serum-free MEM containing $0.05 \% \mathrm{BSA}$ at $37^{\circ} \mathrm{C}$. To estimate the cell number on the plates, a colorimetric assay as described by Shaw and Mercurio [22] was employed with a slight modification as follows. After a certain period of incubation, unattached cells were removed by washing with PBS, while attached cells were fixed with methanol for $5 \mathrm{~min}$. The fixed cells were stained with $0.2 \%$ solution of crystal violet in $2 \%$ ethanol $(200 \mu l /$ well $)$. After incubation for $5 \mathrm{~min}$, wells were washed several times with distilled water, and the crystal violet staining was solubilized with a $1 \%$ SDS solution $(1.5 \mathrm{ml} /$ well $)$. Finally, absorbance of the well contents was determined at $600 \mathrm{~nm}$.

RESULTS

Characteristics of MGM cell lines: Some characteristics of the two cell lines were shown in Table 1. MGM-A revealed a multipolar shape with some cytoplasmic processes, while MGM-S was fibroblast-like. These two cell lines were amelanotic. The doubling time (D.T.) was determined from the logarithmic phase ( 3 and 4 days after seeding). The D.T. of MGM-A and MGM-S was $13.7 \mathrm{hr}$ at the 153rd passage and $19 \mathrm{hr}$ at the 143rd passage, respectively.

Chromosome numbers in MGM-A and MGM-S cells varied considerably. Most of them ranged from 63 to 68 in MGM-A and 44 or 45 and/or from 67 to 76 in MGM-S.

As shown in Fig. 1 and Table 1, colonies in soft agar produced by MGM-A cells were larger in both number and size than those by MGM-S cells. Both cell lines developed tumors in all animals after injection of $10^{7}$ cells. After subcutaneous inoculation of MGM-S cells, tumors were palpable within 2 to 3 weeks and their size reached $20 \mathrm{~mm}$ in diameter within additional 2 weeks. At 4 weeks after intraperitoneal inoculation of MGM-S cells, tumors with a diameter of $20 \mathrm{~mm}$ were observed in the abdominal cavity. In contrast to MGM-S, tumors of MGM-A cells grown into nodules of $20 \mathrm{~mm}$-diameter arose within 10

Table 1. Characteristics of MGM-A and MGM-S

\begin{tabular}{cccccc}
\hline Cell line & Shape & $\begin{array}{c}\text { Doubling } \\
\text { time (hr) }\end{array}$ & $\begin{array}{c}\text { Chromosome } \\
\text { number }\end{array}$ & $\begin{array}{c}\text { Colonies in } \\
{\text { agar } / 10^{3}}^{\text {cells }^{\text {a) }}}\end{array}$ & $\begin{array}{c}\text { Tumor growth } \\
\text { in vivo }\end{array}$ \\
\hline MGM-S & $\begin{array}{c}\text { fibroblast- } \\
\text { like }\end{array}$ & 19 & $\begin{array}{c}\text { near-diploid, } \\
\text { near-triploid }\end{array}$ & 8 & slow \\
MGM-A & multipolar & 13.7 & near-triploid & 229 & rapid $^{\text {b) }}$ \\
\hline
\end{tabular}

a) The number of colonies containing more than 50 cells was determinated at 2 weeks after seeding $10^{3}$ cells (in duplicates) in soft agar.

b) After inoculation of MGM-A cells, subcutaneous or intraperitoneal tumors developed rapidly compared to those of MGM-S cells. 

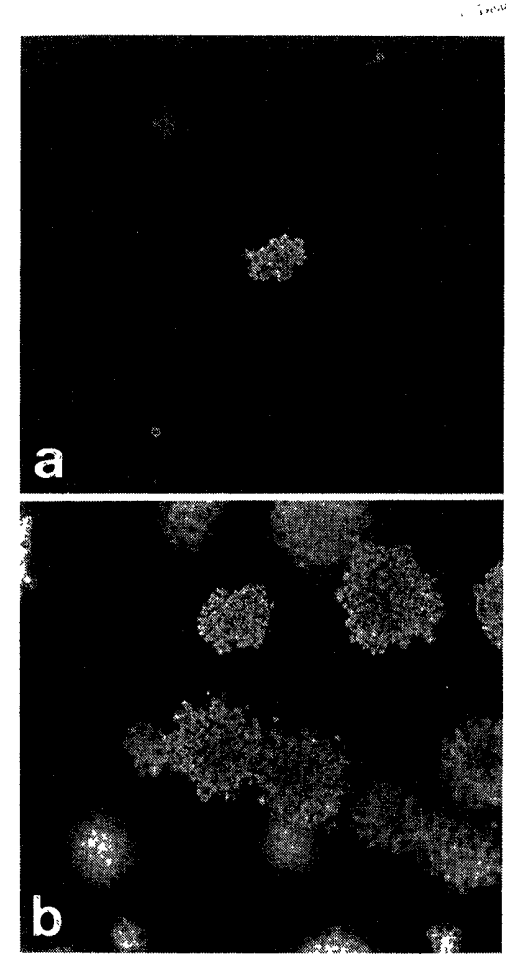

Fig. 1. Phase-contrast photomicrographs of MGM cell lines in soft agar after 2 weeks of incubation. (a), MGM-S; (b), MGM-A. × 100.
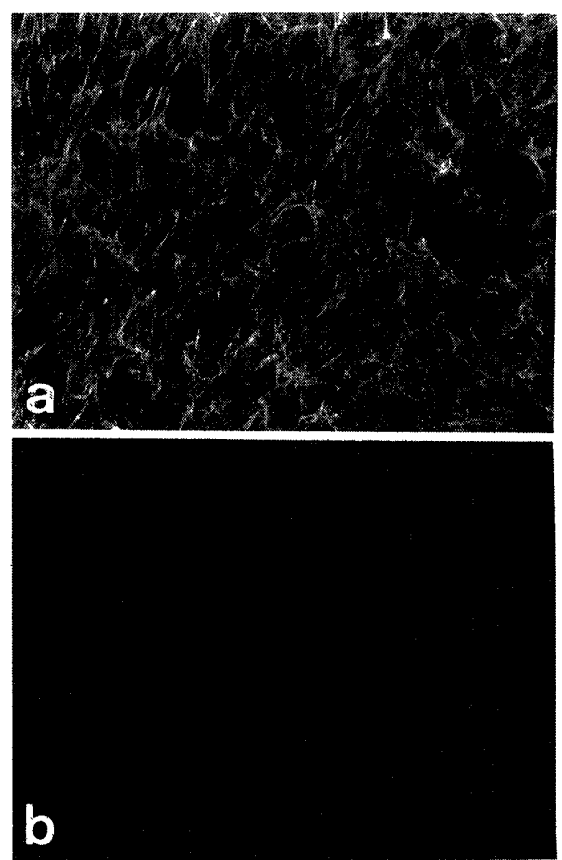

Fig. 2. Localization of cellular fibronectin $(\mathrm{cFN})$ in MGM cell lines by indirect immunofluorescent staining. MGM-S (a) and MGM-A (b) stained with monoclonal antibody to cFN and FITC-conjugated second antibody. FN matrix of MGM-S cell (a) is specifically stained. $\times 180$.

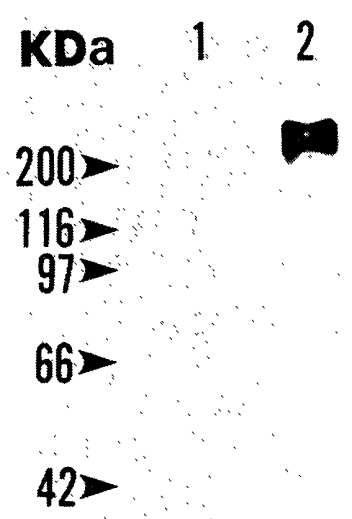

Fig. 3. Western blotting analysis of $\mathrm{cFN}$ in MGM cell lines. The samples were electrophoresed on SDS-polyacrylamide gels $(10 \%)$ under a reducing condition. Lane 1, MGM-A; Lane 2, MGM-S. A sample containing $5 \mu \mathrm{g}$ protein was applied to each lane. Protein molecular weight markers are shown on the left.

days after the subcutaneous or intraperitoneal injection.

Immunological identification of $c F N$ : The fibronectin matrix of MGM-S was specifically stained with monoclonal antibody to cFN and with FITC-conjugated second antibody (Fig. 2). However, immunoreaction with the antibody was not found in MGM-A. Bands of cFN revealed by western blotting analysis were visualized in MGM-S cell lysate (Fig. 3, lane 2).

Affinity to ECM: MGM-A cells with a multipolar shape were widely spread on the dishes coated with Matrigel, fibronectin, laminin or type IV collagen. However, morphological changes of MGM-S cells on these substrates were not observed (Fig. 4).

The adhesion rate of MGM-A cells to ECM components was higher compared to that in controls (Fig. 5). Attachment to laminin was obviously promoted in a dose-dependent manner. On the other hand, no apparent changes in MGM-S cell adhesion was observed.

We then examined the MGM-A and MGM-S cell proliferation stimulated by ECM components. As shown in Fig. 6, MGM-A cells increased in number immediately after seeding on dishes coated with laminin, fibronectin or type IV collagen. The effect of these substrates on MGM-S cell proliferation appeared later compared to MGM-A. Laminin conspicuously promoted not only adhesion but also proliferation of MGM-A cells.

\section{DISCUSSION}

Chromosome abnormalities were observed in both cell lines. The chromosome number of MGM-A was neartriploid, while that of MGM-S was near-diploid or near-triploid. Cytogenetic analysis would provide information on malignancy of these tumor cell lines. The morphology and growth patterns in vitro and in vivo were prominently different between the two cell lines. MGM-A 

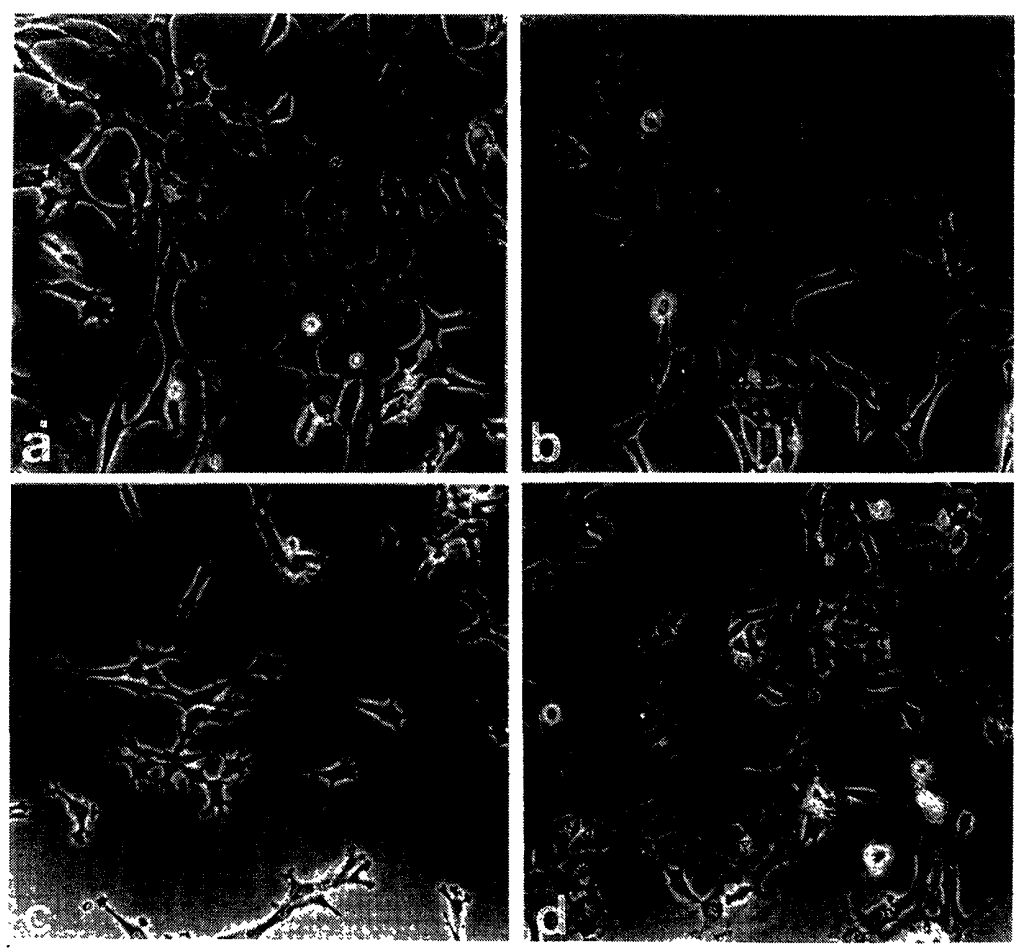

Fig. 4. Phase-contrast photomicrographs taken after $24 \mathrm{hr}$ of incubation in medium containing $10 \%$ fetal bovine serum. Effect of laminin on MGM cell morphology. (a), MGM-S on uncoated dish; (b), MGM-S on laminin-coated dish; (c), MGM-A on uncoated dish; (d), MGM-A on laminin-coated dish. MGM-A cells are widely spread on laminin substrate. However, morphological changes in MGM-S cells are not observed. $\times 200$.
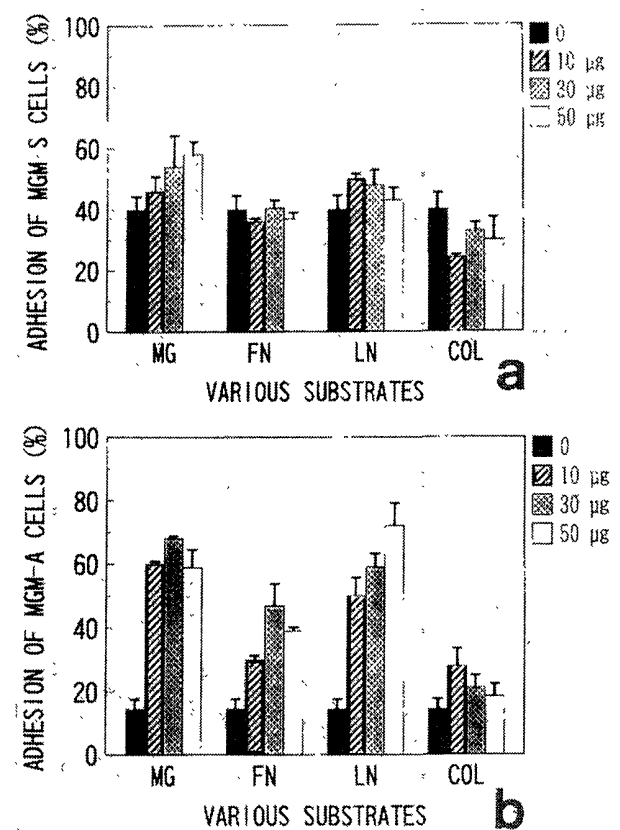

Fig. 5. Adhesion rate of MGM to ECM components. (a), MGM-S; (b), MGM-A. Cells were plated onto dishes coated with Matrigel (MG), fibronectin (FN), laminin (LN) or type IV collagen (COL). After 90 min of incubation in serum-free medium, attached cells were counted. Each vertical bar indicates standard error of the mean.
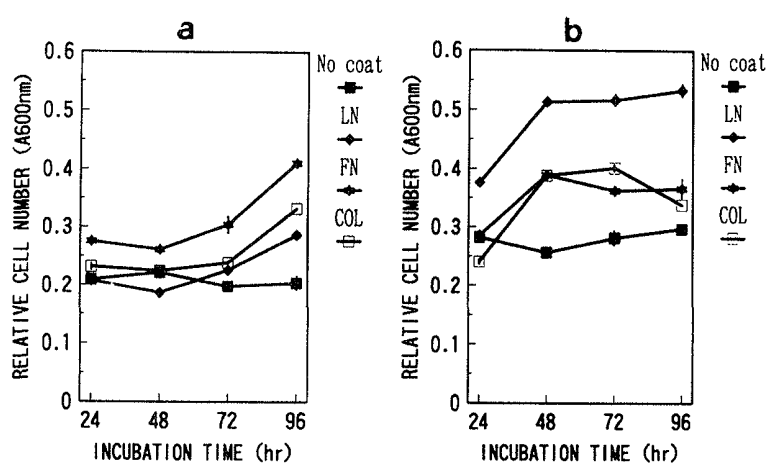

Fig. 6. Effect of ECM components on MGM cell proliferation. Cells were plated onto dishes coated with laminin (LN), fibronectin (FN) or type IV collagen (COL). Cell number was measured by dye-staining method. (a), MGM-S; (b), MGM-A. Each vertical bar indicates standard error of the mean.

cells showed a multipolar shape, while MGM-S cells were fibroblast-like. After inoculation of MGM-A cells to gerbils, subcutaneous and intraperitoneal tumors were rapidly formed. MGM-A had the ability to produce a number of colonies in semi-solid medium. Therefore, MGM-A cells were malignant in property compared with MGM-S cells.

It has been reported that $\mathrm{cFN}$ interacts with actin 
filaments through transmembrane receptors and affects the shape of cells $[4,11]$. In addition, the reduction of fibronectin and its receptors is responsible for acquisition of tumorigenecity and anchorage independent growth [5, 7]. We examined the localization of fibronectin on the cell surface and detected a fibronectin matrix in MGM-S cells but not in MGM-A cells. The difference in shape between the two cell lines may be due to the presence/absence of cell surface fibronectin. However, MGM-S cells were tumorigenic when inoculated into gerbils. Other work has shown that tumorigenic human melanoma cell lines secrete fibronectin [15]. These contradict results indicate the possibility that another cell surface change (i.e. adhesion molecule, matrix metalloproteinases) induces malignant transformation.

ECM proteins are known to correlate with the morphology, adhesion, growth and differentiation of various tumor cells $[3,14,27]$. MGM-A cells had a high affinity for ECM compared with MGM-S cells. Attachment of MGM-A cells to laminin was more prominent than to fibronectin or type IV collagen. Furthermore, the proliferation of MGM-A cells in serum-free medium was promoted by the laminin substrate. The rapid growth of MGM-A cells on ECM components may correspond to that in vivo.

Although there is much evidence that laminin promotes the growth of cultured cells $[12,19]$, the mechanism why laminin stimulates the growth is poorly understood. Porter et al. [20] reported that laminin and fibronectin increase the response of primary and immortalized rat Schwann cells to autocrine growth factors. Therefore, it is possible to postulate that MGM-A cells may secrete autocrine growth factors in the presence of laminin.

Metastatic tumor cells have a high affinity for laminin and express a high level of laminin receptors [16]. However, MGM-A cells are nonmetastatic when inoculated subcutaneously or intraperitoneally. Qian et al. [21] reported that the expression of integrin $\alpha 4 \beta 1$ is inversely correlated with the metastatic potential of the murine B16 melanoma cell lines. It is suggested that the phenotypical change of cell surface adhesion molecules in MGM cell lines may be required for acquisition of the metastatic property. Further characterization of adhesion molecules of MGM-A and MGM-S cells is needed to clarify this assumption.

From the results in this study, MGM-A and MGM-S cell lines may become useful models for the progression of tumor cells.

ACKNOWLEDGEMENT. The authors wish to thank Mr. I. Tsugiyama (Department of Veterinary Anatomy, Faculty of Agriculture, The University of Tokyo) for his expert care in keeping the laboratory gerbils. This work was supported in part by a Grant-in-Aid for Scientific Research Fund from the Ministry of Education, Science and Culture, Japan.
REFERENCES

1. Albelda, S. M., Mette, S. A., Elder, D. E., Stewart, R., Damjanovich, L., Herlyn, M., and Buck, C. A. 1990. Integrin distribution in malignant melanoma: Association of the $\beta 3$ subunit with tumor progression. Cancer Res. 50: 6757-6764.

2. Aresu, O., Nicolo, G., Allavena, G., Melchiori, A., Schmidt, J., Kopp, J. B., d'Amore, E., Chader, G. J., and Albini, A. 1991. Invasive activity, spreading on and chemotactic response to laminin are properties of high but not low metastatic mouse osteosarcoma cells. Invas. Metast. 11: 2-13.

3. Begovac, P. C., Hall, D. E., and Shur, B. D. 1991. Laminin fragment E8 mediates PC12 cell neurite outgrowth by binding to cell surface $\beta 1,4$ galactosyltransferase. J. Cell Biol. 113: 637-644.

4. Burridge, K., Fath, K., Kelly, T., Nuckolls, G., and Turner, C. 1988. Focal adhesions: transmembrane junctions between the extracellular matrix and the cytoskeleton. Annu. Rev. Cell. Biol. 4: 487-525.

5. Chen, J.-M. and Chen, W.-T. 1987. Fibronectin-degrading proteases from the membrane: of transformed cells. Cell 48: 193-203.

6. Gahamberg, C. G. and Hakomori, S. 1973. Altered growth behavior of malignant cells associated with changes in externally labeled glycoprotein and glycolipid. Proc. Natl. Acad. Sci. U.S.A. 70: 3329-3333.

7. Giancotti, F. G. and Ruoslahti, E. 1990. Elevated levels of the $\alpha 5 \beta 1$ fibronectin receptor suppress the transformed phenotype of Chinese hamster ovary cells. Cell 60: 849-859.

8. Greene, L. A. and Tischler, A. S. 1976. Establishment of a noradrenergic clonal line of rat adrenal pheochromocytoma cells which respond to nerve growth factor. Proc. Natl. Acad. Sci. U.S.A. 73: 2424-2428.

9. Hashimoto, O., Miyamoto, K., Moritomo, T., Saito, H., Watanabe, T., and Mochizuki, K. 1993. Characterization of cultured cells derived from Mongolian gerbil's (Meriones unguiculatus) ascitic malignant melanoma. J. Vet. Med. Sci. 55: 227-232.

10. Hynes, R. O. 1973. Alteration of cell-surface proteins by viral transformation and by proteolysis. Proc. Natl. Acad. Sci. U.S.A. 70: 3170-3174.

11. Hynes, R. O. and Destree, A. T. 1978. Relationships between fibronectin (LETS protein) and actin. Cell 15: 875-886.

12. Kleinman, H. K., Cannon, F. B., Laurie, G. W., Hassell, J. R., Aumailley, M., Terranova, V. P., Martin, G. R., and Dubois-Dalcq, M. 1985. Biological activities of laminin. $J$. Cell. Biochem. 27: 317-325.

13. Laemmli, U. K. 1970. Cleavage of structural proteins during the assembly of the head of bacteriophage T4. Nature (Lond.) 227: 680-685.

14. Levesque, J. P., Hatzfeld, A., and Hatzfeld, J. 1991. Mitogenic properties of major extracellular proteins. Immunol. Today 12: 258-262.

15. Ludwig, C., Harper, J., Payne, C., Nagle, R., Bastert, G., and Trent, J. 1988. Cellular and genetic properties of two melanoma cell lines established from the same tumor. Anticancer Res. 8: 9-16.

16. Mafune, K., Ravikumar, T. S., Wong, J. M., Yow, H., Chen, L. B., and Steele, G. D. Jr. 1990. Expression of a $\mathrm{Mr}$ 32000 laminin binding protein messenger RNA in human 
colon carcinoma correlates with disease progression. Cancer Res. 50: 3888-3891.

17. McCarthy, J. B., Basara, M. L., Palm, S. L., Sas, D. F., and Furcht, L. T. 1985. The role of cell adhesion proteinslaminin and fibronectin-in the movement of malignant and metastatic cells. Cancer Metast. Rev. 10: 245-254.

18. Moritomo, T., Saito, H., Watanabe, T., and Mochizuki, K. 1991. Tissue culture study on Mongolian gerbil's (Meriones unguiculatus) malignant melanoma. Exp. Anim. (Tokyo) 40: $385-388$

19. Ohki, K. and Kohashi, O. 1994. Laminin promotes proliferation of bone marrow-derived macrophages and macrophage cell lines. Cell Struct. Funct. 19: 63-71.

20. Porter, S., Glaser, L., and Bunge, R. P. 1987. Release of autocrine growth factor by primary and immortalized Schwann cells. Proc. Natl. Acad. Sci. U.S.A. 84: 7768-7772.

21. Qian, F., Vaux, D. L., and Weisseman, I. L. 1994. Expression of the integrin $\alpha 4 \beta 1$ on melanoma cells can inhibit the invasive stage of metastasis formation. Cell 77 : 335-347.

22. Shaw, L. M. and Mercurio, A. M. 1993. Regulation of $\alpha 6 \beta 1$ integrin laminin receptor function by the cytoplasmic domain of the $\alpha 6$ subunit. J. Cell Biol. 123: 1017-1025.

23. Sweeney, T. M., Kibbey, M. C., Zain, M., Fridman, R., and Kleinman, H. K. 1991. Basement membrane and SIKVAV laminin-derived peptide promote tumor growth and metastasis. Cancer Metast. Rev. 10: 245-254.

24. Terranova, V. P., Liotta, L. A., Russo, R. G., and Martin, G. R. 1982. Role of laminin in the attachment and metastasis of murine tumor cells. Cancer Res. 42: 2265-2269.

25. Terranova, V. P., Rao, C. N., Kalebic, T., Margulies, I. M., and Liotta, L. A. 1983. Laminin receptor on human breast carcinoma cells. Proc. Natl. Acad. Sci. U.S.A. 80: $444-448$.

26. Terranova, V. P., Williams, J. E., Liotta, L. A., and Martin, G. R. 1984. Modulation of the metastatic activity of melanoma cells by laminin and fibronectin. Science 226 : 982-985.

27. Wilson, J. R. and Weiser, M. M. 1992. Colonic cancer cell (HT29) adhesion to laminin is altered by differentiation: Adhesion may involve galactosyltransferase. Exp. Cell Res. 201: $330-334$. 